\title{
The Effect of SH2B1 Variants on Expression of Leptin- and Insulin-Induced Pathways in Murine Hypothalamus
}

\author{
Johanna Giuranna ${ }^{a}$ Anna-Lena Volckmar ${ }^{a, b}$ Anna Heinen ${ }^{a}$ \\ Triinu Peters $^{a}$ Börge Schmidt ${ }^{c}$ Anne Spieker ${ }^{a}$ Helena Straub $^{a}$ \\ Harald Grallert $^{d}$ Timo D. Müller ${ }^{\mathrm{e}}$ Jochen Antel ${ }^{\mathrm{a}}$ Ute Haußmann ${ }^{f}$ \\ Hans Klafkif,g Rui Liangyou ${ }^{\mathrm{h}}$ Johannes Hebebrand ${ }^{\mathrm{a}}$ Anke Hinney ${ }^{\mathrm{a}}$ \\ ${ }^{a}$ Department of Child and Adolescent Psychiatry, Psychosomatics and Psychotherapy, \\ University Hospital Essen, University of Duisburg-Essen, Essen, Germany; ${ }^{b}$ Institute of \\ Pathology, Heidelberg University Hospital, Heidelberg, Germany; ' Institute for Medical \\ Informatics, Biometry and Epidemiology (IMIBE), University Hospital Essen, University of

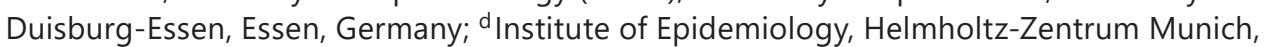

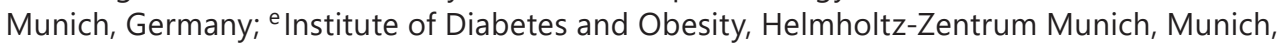 \\ Germany; ${ }^{f}$ Department of Psychiatry and Psychotherapy, Faculty of Medicine, University \\ Hospital Essen, Essen, Germany; ${ }^{9}$ Department of Psychiatry and Psychotherapy, University \\ Medical Center Göttingen (UMG), Georg-August-University Göttingen, Göttingen,

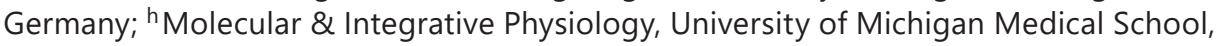 \\ Ann Arbor, MI, USA
}

\section{Keywords}

GWAS · SH2B1 $\cdot$ JAK $\cdot$ STAT $\cdot$ IRS $\cdot$ Expression genome-wide $\cdot$ Locus

\begin{abstract}
Objective: We aimed to determine the effect of human $\mathrm{SH} 2 \mathrm{~B} 1$ variants on leptin and insulin signaling, which are major regulators of energy homeostasis, on the RNA level. Methods: We analyzed the expression of infrequent alleles of seven SH2B1 variants (Arg67Cys, Lys150Arg, Thr175Ala, Thr343Met, Thr484Ala, Ser616Pro, and Pro689Leu) in response to insulin or leptin cell stimulation. Two of these were identified in own mutation screens, the others were predicted to be deleterious or to serve as controls. The variants were analyzed in a homologous system of mouse hypothalamic cells. Changes in expression of downstream genes were measured. Student's t-test for independent samples was applied, and effect sizes using Cohen's d
\end{abstract}


with $95 \%$ confidence intervals were therefore calculated. Results: In 34 of 54 analyzed genes involved in leptin (JAK/STAT or AKT) signaling, variants nominally changed expression. The expression of three genes was considerably increased ( $p$ values $\leq 0.001$ : Gbp2b (67Cys; $d=$ $25.11(-3.53,-2.70))$, Irf9 (689Leu; $d=44.65(-2.57,-2.26))$, and Isg15 (150Arg; $d=20.35(-2.19$, $-1.57))$ ). Of 32 analyzed genes in the insulin signaling pathway, the expression of 10 genes nominally changed $(\mathrm{p} \leq 0.05)$, three resulted in $\mathrm{p}$ values $\leq 0.01$ (Cap1 (150Arg; $d=7.48(-0.62$, $-0.24)$ ), Mapk1 (343Met; $d=-6.80(0.17,0.45))$, and Sorbs1 (689Leu; $d=7.82(-1.60,-0.64))$ ). Conclusion: The increased expression of genes in the leptin (JAK/STAT or AKT) signaling pathway implies that the main mode of action for human SH2B1 mutations might affect leptin signaling rather than insulin signaling.

(c) 2018 The Author(s)

Published by S. Karger GmbH, Freiburg

\section{Introduction}

The Src homology 2B adaptor protein 1 gene (SH2B1) is derived from genome-wide association studies (GWAS) for BMI and obesity [1-4]. The infrequent alleles of single nucleotide polymorphisms (SNPs) at SH2B1 confer polygenic effects on obesity. A coding SNP in SH2B1 (rs7498665 Thr484Ala) $[1,2]$ and variants in linkage disequilibrium are associated with obesity and related traits $[3,4]$. The association has been replicated in different ethnicities and age groups [5-11]. In addition, a copy number variation (CNV; 200-500 kb) covering a region on chr16p11.2 that harbors $S H 2 B 1$ is associated with weight phenotypes. While a deletion in this region is associated with increased BMI and obesity risk $[12,13]$, the reciprocal duplication is associated with underweight [14].

Two independently generated Sh $2 b 1$ knockout (KO) models display an altered body weight. Sh2b1 KO mice are obese, hyperphagic, hyperlipidemic, leptin- and insulin-resistant, hyperglycemic, and glucose-intolerant [15-17]. A genetic rescue of the SH2B1 beta isoform in neurons eliminated both obesity and insulin resistance phenotypes [17]. The Drosophila melanogaster KO led to increased fat mass although the overall body size shrank. In contrast to the murine model [17], a neuronal KO of $S h 2 b 1$ was not sufficient to elicit the phenotype in Drosophila [18].

Leptin and insulin signaling are the main pathways involved in SH2B1 action on energy homeostasis [19]. SH2B1 promotes leptin signaling by stimulating Janus kinase (JAK1 and JAK2) activity and the assembly of JAK2 / insulin receptor substrate (IRS1 and IRS2) complexes [20-22]. SH2B1 also enhances insulin receptor autophosphorylation after insulin stimulation and protects IRS and JAK from dephosphorylation [23,24]. Additionally, JAK and IRS are also downstream effectors of growth hormone (GH), insulin like growth factor 1 (IGF-1), (nerve growth factor (NGF) and brain-derived neurotrophic factor (BDNF), leading to the assumption that the signaling of all these hormones is potentially affected by SH2B1 mutations [19].

We previously reported a rare variant ( $\beta$ Thr656Ile/ $\gamma$ Pro674Ser), affecting the beta and gamma splice variants of $S H 2 B 1$. The infrequent variant allele was detected exclusively in 3 out of 11,406 obese individuals but not in 4,568 normal-weight controls [8]. When analyzing the impact of the obesity-associated SNP rs7498665 (Thr484Ala) and the rare variant $\beta$ Thr656Ile $/ \gamma$ Pro674Ser on STAT3-mediated leptin signaling, we did not observe functional effects [8].

SH2B1 mutations were detected among 800 obese children and adolescents with insulin resistance (Pro90His, Thr175Asn, Pro322Ser, Phe344Leufs*20, Thr564Ala, Ala663Val, Ala723Val) $[25,26]$. All variants impaired GH-induced cell motility when present in the 
Giuranna et al.: The Effect of SH2B1 Variants on Expression of Leptin- and Insulin-

Induced Pathways in Murine Hypothalamus

alpha isoform of SH2B1. Except for the frameshift variant (Phe344Leufs*20) that lacks the SH2 domain, all variants interfered with insulin- or leptin-induced IRS2 phosphorylation [26].

We analyzed the role of $S H 2 B 1$ variants in pathways of energy homeostasis by their interaction with insulin receptor and leptin receptor signaling. We chose murine hypothalamic cells, as the hypothalamus is one of the key players in energy balance regulation [2]. Hence, we assayed the functional implications of seven human SH2B1 variants at the RNA level. The variants were chosen as they were associated with obesity (Thr484Ala), located in functional domains of SH2B1 (dimerization domain: Arg67Cys; nuclear localization domain: Lys150Arg; pleckstrin homology domain: Thr343Met; SH2 domain: Ser616Pro) and predicted (by PolyPhen 2) to have a functional effect (probably damaging) or to serve as potential controls (Thr175Ala, Pro689Leu).

\section{Material and Methods}

\section{Mutation Screen}

The coding region of $S H 2 B 1$, located at chr16: 28,858,010 - 28,885,533 (hg18/ NCBI 36; accession number: ENSG00000178188, MIM: 608937), was screened for mutations by denaturing high pressure liquid chromatography (dHPLC) using the Transgenomic wave genetic analyzer (Transgenomic, Crewe, UK) and Sanger re-sequencing as described previously [27] in 93 lean adults (26.7\% males, age $21.18 \pm 6.99$ years, BMI $17.98 \pm 1.08 \mathrm{~kg} / \mathrm{m}^{2}$ ). This study group was selected in order to identify further variants in $S H 2 B 1$ that might rather exert a weight-lowering effect. Detailed information regarding used temperatures and primers for PCR and dHPLC analysis can be obtained from the authors. All PCR amplicons with dHPLC patterns derived from the wild-type pattern were re-sequenced as described previously [8]. At least two experienced individuals independently assigned the genotypes; discrepancies were solved either by reaching consensus or by re-genotyping.

The non-synonymous variants were then genotyped in a sample of 355 trios comprising a child with (extreme) obesity and both parents by MALDI TOF (index patients: 45.37\% males, age $13.72 \pm 3.12$ years, BMI $32.02 \mathrm{~kg} / \mathrm{m}^{2}$; BMI Standard Deviation Score (BMI SDS) $4.13 \pm 2.06$; parents: age: $42.85 \pm 6.14$, BMI 29.95 $\left.\pm 6.15 \mathrm{~kg} / \mathrm{m}^{2}[8,28]\right)$, in an independent sample of 453 cases $(42.60 \%$ males, age $14.37 \pm 3.75$ years, BMI $30.28 \mathrm{~kg} / \mathrm{m}^{2}$, BMI SDS $4.51 \pm 2.15$ ), and in 342 controls (39.08\% males, age $26.08 \pm 5.75$ years, BMI $18.09 \pm$ $1.14 \mathrm{~kg} / \mathrm{m}^{2}$ [29]). These studies were approved by the Ethics Committees of the respective Universities and were performed in accordance with the Declaration of Helsinki.

Cells

To provide insight into the hypothalamus as the main weight regulatory area of the brain, we chose a murine hypothalamic cell line, which expresses both insulin receptor and leptin receptor. The hypothalamic CLU188 cells ('Adult mouse hypothalamic cell line mHypoA-2/28 CLU188';Biozol, Eching, Germany) were cultured in DMEM (Life Technologies, Carlsbad, CA, USA) with 10\% fetal bovine serum (FBS; Merck Millipore, Darmstadt, Germany) and penicillin-streptomycin (Life Technologies, Carlsbad, CA, USA) at $37{ }^{\circ} \mathrm{C}$ in humidified atmosphere containing $5 \% \mathrm{CO}_{2}$. After knockdown of Sh2b1 via co-transfected Zink finger nuclease (Sigma Aldrich, St. Louis, MO, USA) and a plasmid containing the selection cassette for neomycin and green fluorescent protein (GFP) (obtained from Sigma Aldrich; supplementary data, available at http://content. karger.com/ProdukteDB/produkte.asp?doi=486962), G418 (300 $\mathrm{gg} / \mathrm{ml}$; Life Technologies) was added to the media to maintain the $S h 2 b 1$ knockout (for details see supplementary data, available at $h t t p: / / c o n t e n t$. karger. com/ProdukteDB/produkte.asp?doi=486962).

The Sh2b1 KO cells were transiently transfected (calcium phosphate method, see supplementary data, available at http://content.karger.com/ProdukteDB/produkte.asp?doi=486962) with human SH2B1 alpha splice form clones (wild-type, 67Cys, 150Arg, 175Ala, 343Met, 484Ala, 616Pro, 689Leu) under a CMV promoter (all clones were provided by Origene, mutation induction by Genscript, Piscataway, NJ, USA). The variants were chosen as they were associated with obesity, located in functional domains of SH2B1, and predicted by PolyPhen 2 to have a functional effect, or to serve as potentially 'like wild-type' controls as predicted by PolyPhen 2 (table 1). After $24 \mathrm{~h}$, the cells were stimulated with either leptin or insulin (100 ng/ $\mathrm{ml}$ each; Sigma Aldrich) for $1 \mathrm{~h}$ and immediately harvested and frozen at $-80^{\circ} \mathrm{C}$. As a negative control, non- 
Giuranna et al.: The Effect of SH2B1 Variants on Expression of Leptin- and InsulinInduced Pathways in Murine Hypothalamus

Table 1. Non-synonymous variants of human SH2B1 chosen for in vitro analysis

\begin{tabular}{lllll}
\hline $\begin{array}{l}\text { Variant: amino acid exchange } \\
\text { (rs-number) }\end{array}$ & MAF in CEU & PolyPhen2 (Class:Score) & Functional domain & Reference \\
\hline $\begin{array}{l}\text { Arg67Cys } \\
\text { (rs781063312) }\end{array}$ & NA & $\begin{array}{l}\text { probably damaging } \\
(1.000)\end{array}$ & dimerization & dbSNP \\
\hline $\begin{array}{l}\text { Lys150Arg } \\
\text { (rs141195883) }\end{array}$ & 0.000 & $\begin{array}{l}\text { possibly damaging } \\
(0.952)\end{array}$ & $\begin{array}{l}\text { nuclear localization } \\
\text { domain }\end{array}$ & $\begin{array}{l}\text { dbSNP, lean controls in } \\
\text { this study }\end{array}$ \\
\hline $\begin{array}{l}\text { Thr175Ala } \\
\text { (rs181294111) }\end{array}$ & 0.001 & $\begin{array}{l}\text { benign } \\
(0.036)\end{array}$ & none dbSNP \\
\hline $\begin{array}{l}\text { Thr343Met } \\
\text { (rs139298340) }\end{array}$ & 0.000 & $\begin{array}{l}\text { probably damaging } \\
(0.998)\end{array}$ & Pleckstrin homology & dbSNP \\
\hline $\begin{array}{l}\text { Thr484Ala } \\
\text { (rs7498665) }\end{array}$ & 0.331 & $\begin{array}{l}\text { benign } \\
(0.000)\end{array}$ & none & [8], lean controls in this \\
\hline $\begin{array}{l}\text { Ser616Pro } \\
\text { (rs142515048) }\end{array}$ & 0.000 & $\begin{array}{l}\text { possibly damaging } \\
(0.876)\end{array}$ & Src homology 2 & dbSNP \\
\hline $\begin{array}{l}\text { Pro689Leu } \\
\text { nA }\end{array}$ & $\begin{array}{l}\text { benign } \\
(0.000)\end{array}$ & none & dbSNP \\
\hline
\end{tabular}

MA = Minor allele frequency; CEU = Northern Europeans from Utah.

dbSNP (www.ncbi.nlm.nih.gov/snp/), PolyPhen 2 (www.genetics.bwh.harvard.edu/pph2/).

transfected cells were also treated and harvested as just described. We also used non-stimulated CLU188 cells as an additional experimental control.

The identity of the mouse cells was confirmed by the DSMZ (www.dsmz.de).

\section{Expression Analysis}

The stimulated cells were thawed, and the RNA was extracted using the RNAeasy Mini prep (Qiagen, Hilden, Germany). Reverse transcription of 25 ng RNA was performed with RT $^{2}$ First Strand Kit (Qiagen). To gain further insight into the impact of the analyzed SH2B1 variants on insulin and leptin signaling, insulin signaling pathway and JAK/STAT signaling pathway, RT ${ }^{2}$ Profiler PCR arrays (Qiagen) were used according to the manufacturer's handbook on a StepOnePlus ${ }^{\text {TM }}$ Real-Time PCR System (qRT-PCR; Life Technologies) with the respective software. The threshold for analysis was Ct 35 as higher Ct values indicate very low initial mRNA amounts. Here, small pipetting errors would cause strong changes in expression. The experiments were performed in duplicates or triplicates (means, standard deviations, and exact replicate numbers are indicated in the figures).

\section{Statistical Analyses}

To analyze the obesity association in the case/control sample, Fisher's exact test (allelic association) was done with PLINK [30]. Additionally, an asymptotic, 2-tailed p value for the transmission disequilibrium test was calculated with PLINK for the family based sample. If not stated otherwise, all p values are asymptotic, two-sided and not corrected for multiple testing.

For the in vitro tests and the quantitative expression analysis, all measured Ct values of the target genes were normalized to the mean of moderately expressed housekeeping genes using the $\Delta \Delta \mathrm{Ct}$ method. Then the fold change was calculated in order to compare the final value and the initial value (wild-type) for each gene. Mean differences in amounts of mRNA between variants were tested applying independent samples t-test. To analyze the homogeneity of variances, the Levene's test was used. These analyses were performed using IBM $^{\circledR}$ SPSS ${ }^{\circledR}$ Statistics 24.0.1 for Windows (IBM, Armonk, NY, USA). Given p values are nominal and two-sided unless stated otherwise. A significance level of $\mathrm{p} \leq 0.05$ was applied, and for the figures only $\mathrm{p}$ values $\leq 0.01$ 
were considered. Effect sizes (Cohen's d) of nominally altered gene expression patterns for each SH2B1 variant were calculated according to the formula:

$$
\mathrm{d}=\mathrm{X}_{\mathrm{var}}-\mathrm{X}_{\mathrm{wt}} / \mathrm{SD}_{\mathrm{p}}
$$

where $\mathrm{X}$ was the mean of calculated $\Delta \mathrm{Ct}$ values of genes for each SH2B1 variant (var) or for wild-type respectively, and $\mathrm{SD}_{\mathrm{p}}$ is the pooled standard deviation calculated as:

$$
S D p=\sqrt{\frac{S D^{2} v a r+S D^{2} w t}{2}}
$$

being $\mathrm{SD}_{\mathrm{var}}$ the standard deviation of genes for each variant and $\mathrm{SD}_{\mathrm{wt}}$ the standard deviation of genes for the wild-type. Effect sizes were interpreted as small (0.2), medium (0.2-0.5) and large (>0.8) [31].

\section{Results}

\section{Mutation Screen}

In the 93 lean adults, we detected two non-synonymous variants (rs141195883 Lys150Arg and rs7498665 - Thr484Ala); both have previously been reported [8, 25]. The infrequent allele of Lys150Arg was not associated with obesity in 355 trios comprising a child with (extreme) obesity and both parents (transmission equilibrium; nominal $p=0.32$ ) or an independent sample of 453 children and adolescents with extreme obesity versus 342 lean adults (nominal $\mathrm{p}=0.51$ ). Minor allele frequency was low $(0.14 \%)$ so that the association analyses were underpowered. For rs7498665, we previously described an association with obesity in our study groups (nominal $p=0.009$ in 705 trios with obesity, $\mathrm{OR}=1.23$ ) [8].

\section{Expression Analyses}

To analyze the effects of the SH2B1 variants (supplemental fig. 1, available at http:// content.karger.com/ProdukteDB/produkte.asp?doi=486962) on expression downstream of STAT, AKT and IR/IRS, arrays for gene expression of the JAK/STAT and insulin pathways were used. Although the respective qRT-PCR panels allow a wide range of different expression analyses, we focused on the genes of the pathways that are most relevant for energy homeostasis maintenance in the brain.

After stimulation with leptin, the expression of downstream genes in JAK/STAT, AKT, interferon (IFN), and interleukin signaling were altered by at least one of the $S H 2 B 1$ variants compared to wild-type (table 2; supplemental table 1, available at http://content.karger.com/ ProdukteDB/produkte.asp?doi=486962). Of the 84 genes included in the panel, 54 genes showed expression in the range necessary for a valid analysis (Ct threshold below 35 cycles). Of these, 34 genes were nominally affected by at least one of the variants in SH2B1 (supplemental fig. 2, available at http://content.karger.com/ProdukteDB/produkte. asp? doi=486962). Changes in expression (fold change) of Gbp2b (67Cys, $0.12 \pm 0.18$; $p_{\text {nominal }}=0.0002$ ), Irf9 $\left(\alpha 689 \mathrm{Leu}, 0.19 \pm 0.05 ; p_{\text {nominal }}=0.000018\right)$, Isg $15\left(150 \mathrm{Arg}, 0.27 \pm 0.13 ; p_{\text {nominal }}=0.0003\right)$ were nominally significant ( $\mathrm{p} \leq 0.001$; fig. 1 ). The differences at the transcription levels were never limited to genes in a specific part of the pathway but rather distributed across all genes within leptin signaling. For SNP rs7498665 (484Ala), we observed for 29 genes (out of 54 genes analyzed for all mutations) that the expression was too low for a proper analysis, despite an expression of four housekeeping genes that was comparable to the other SH2B1 variants. Hence we did not include these 29 genes in our analysis for this SNP. Among the remaining 25 genes, 484Ala increased expression of Pias2, Stat2, Stub1, and Yy1 nominally (table 2).

After insulin stimulation, four of the variants altered the expression of at least one gene in the insulin signaling pathway (table 3; supplemental table 2, available at http://content. karger.com/ProdukteDB/produkte.asp?doi=486962). Of the 32 genes that were expressed on 
Giuranna et al.: The Effect of SH2B1 Variants on Expression of Leptin- and InsulinInduced Pathways in Murine Hypothalamus

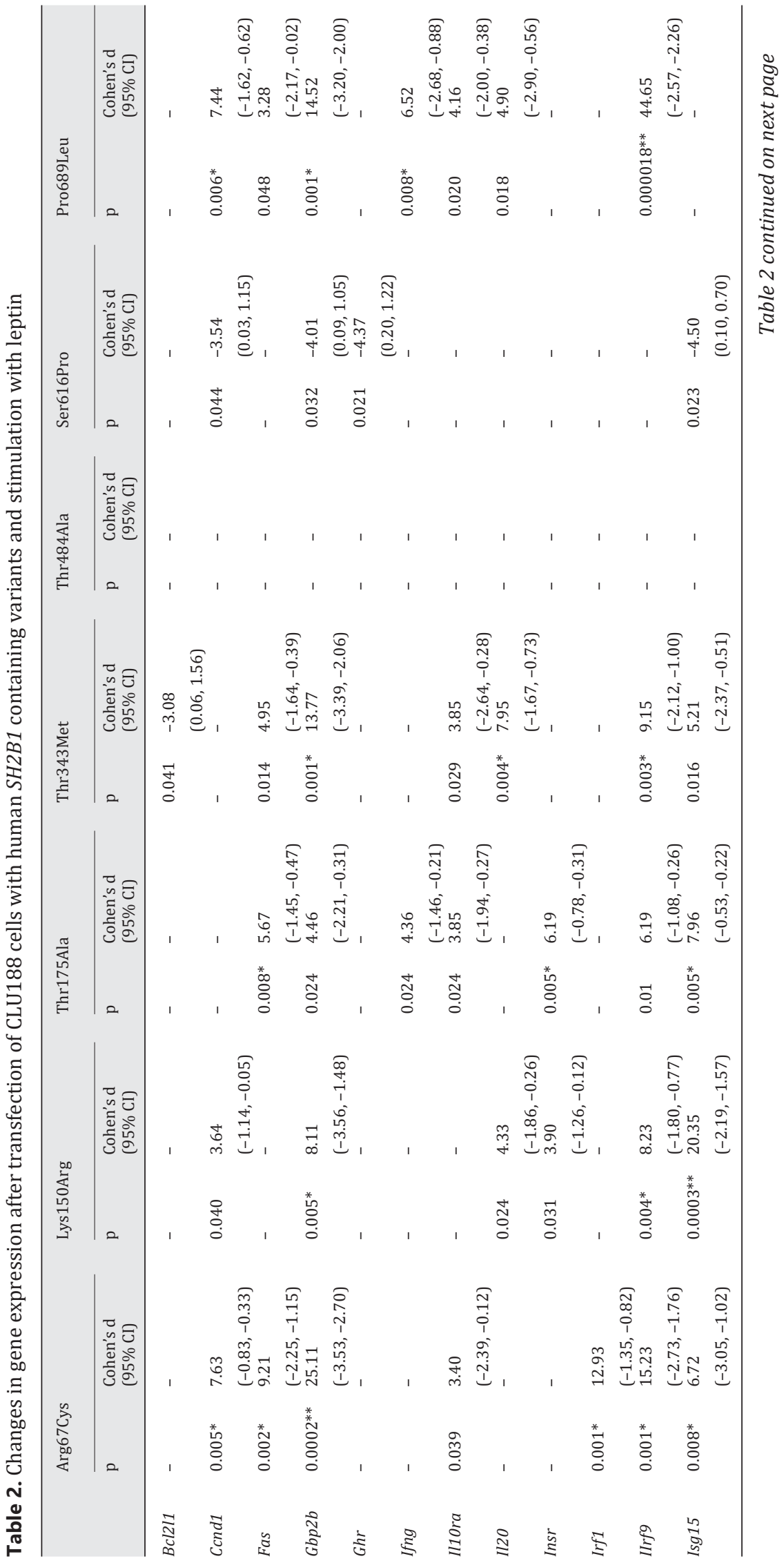


Giuranna et al.: The Effect of SH2B1 Variants on Expression of Leptin- and InsulinInduced Pathways in Murine Hypothalamus

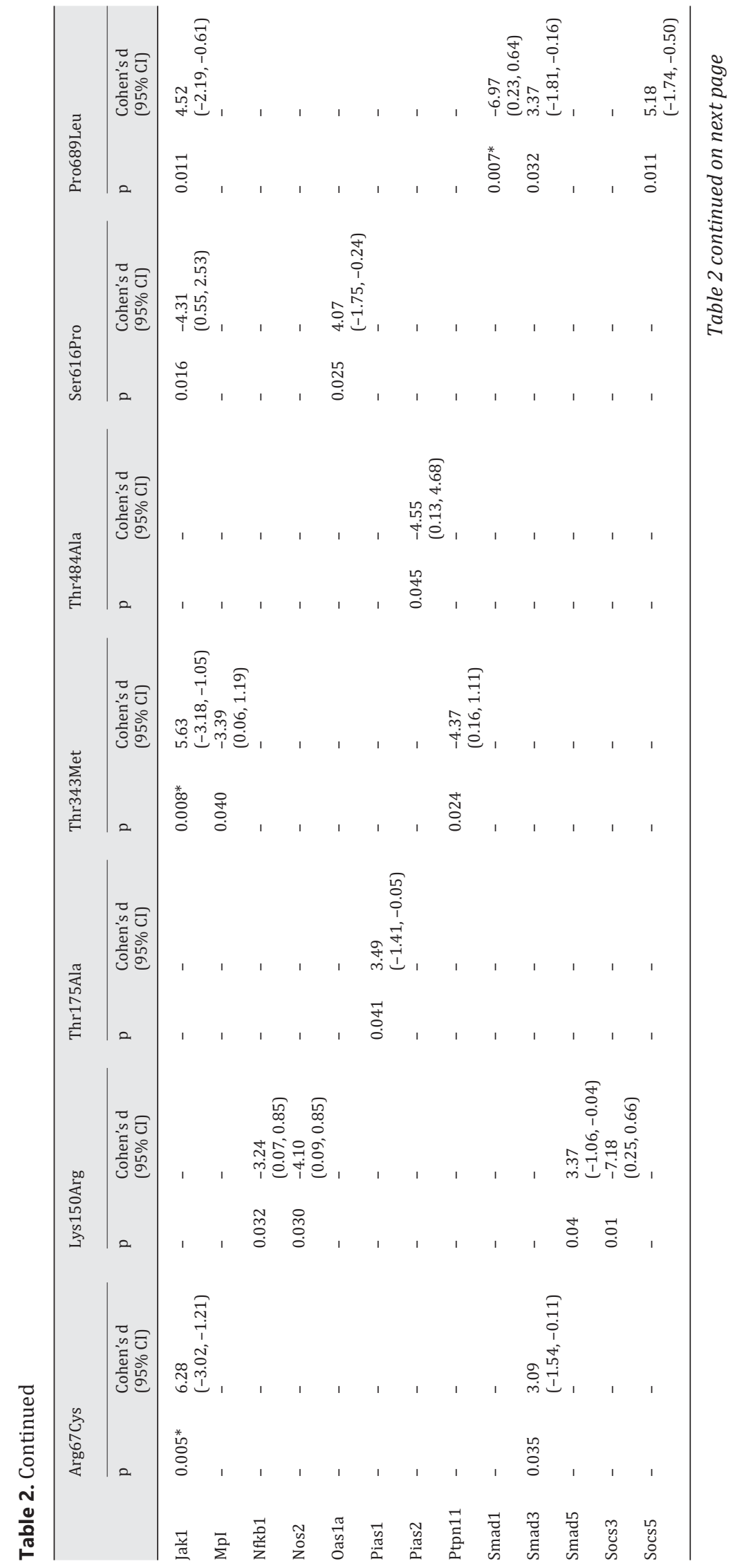


Giuranna et al.: The Effect of $S H 2 B 1$ Variants on Expression of Leptin- and InsulinInduced Pathways in Murine Hypothalamus

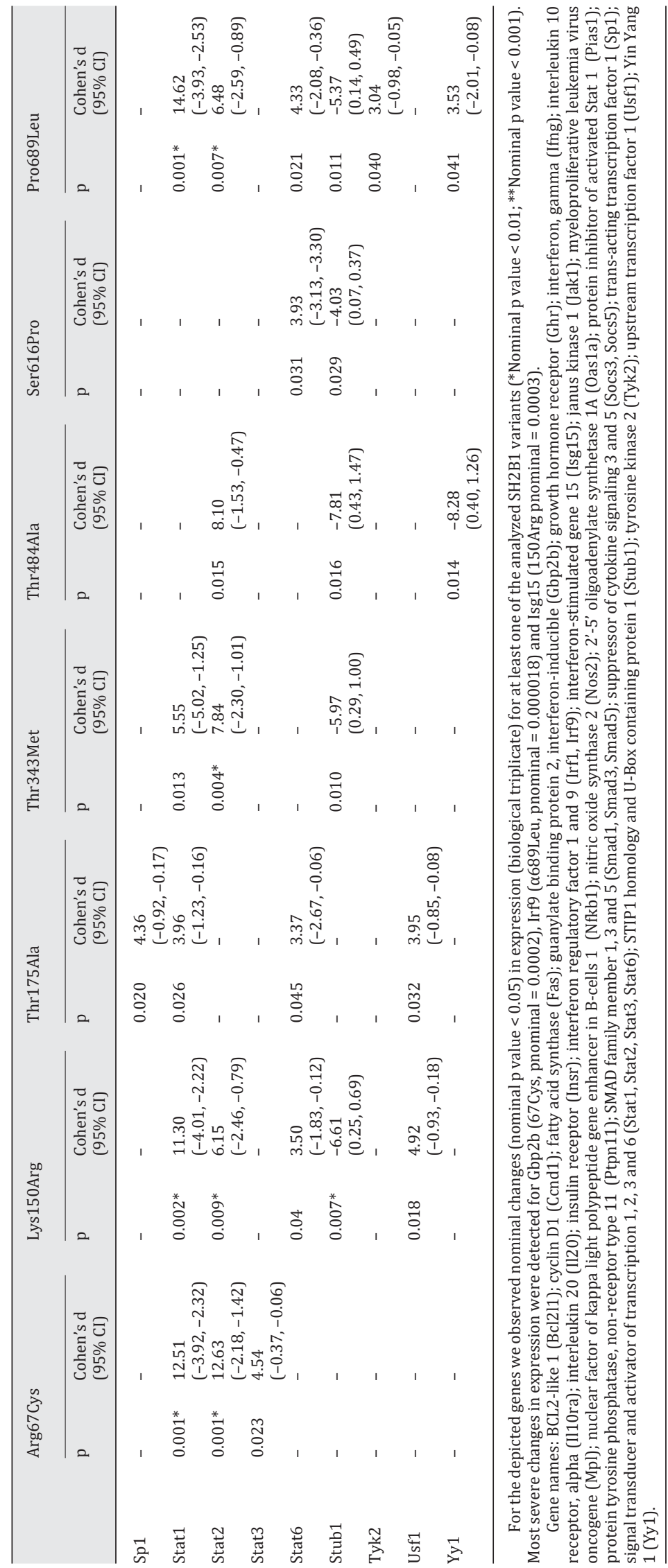




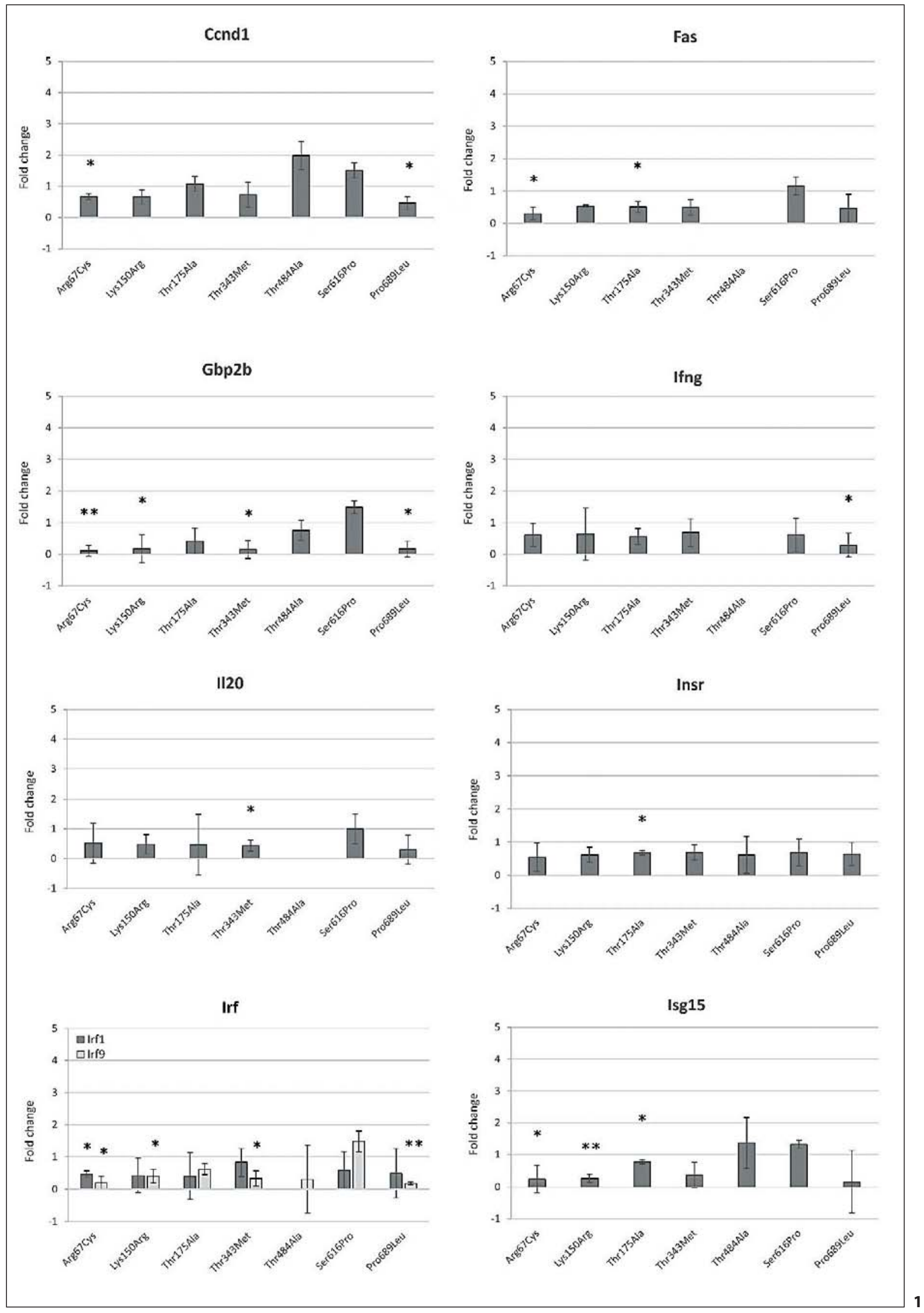

(For rest of figure and legend see next page.) 
Giuranna et al.: The Effect of SH2B1 Variants on Expression of Leptin- and Insulin-

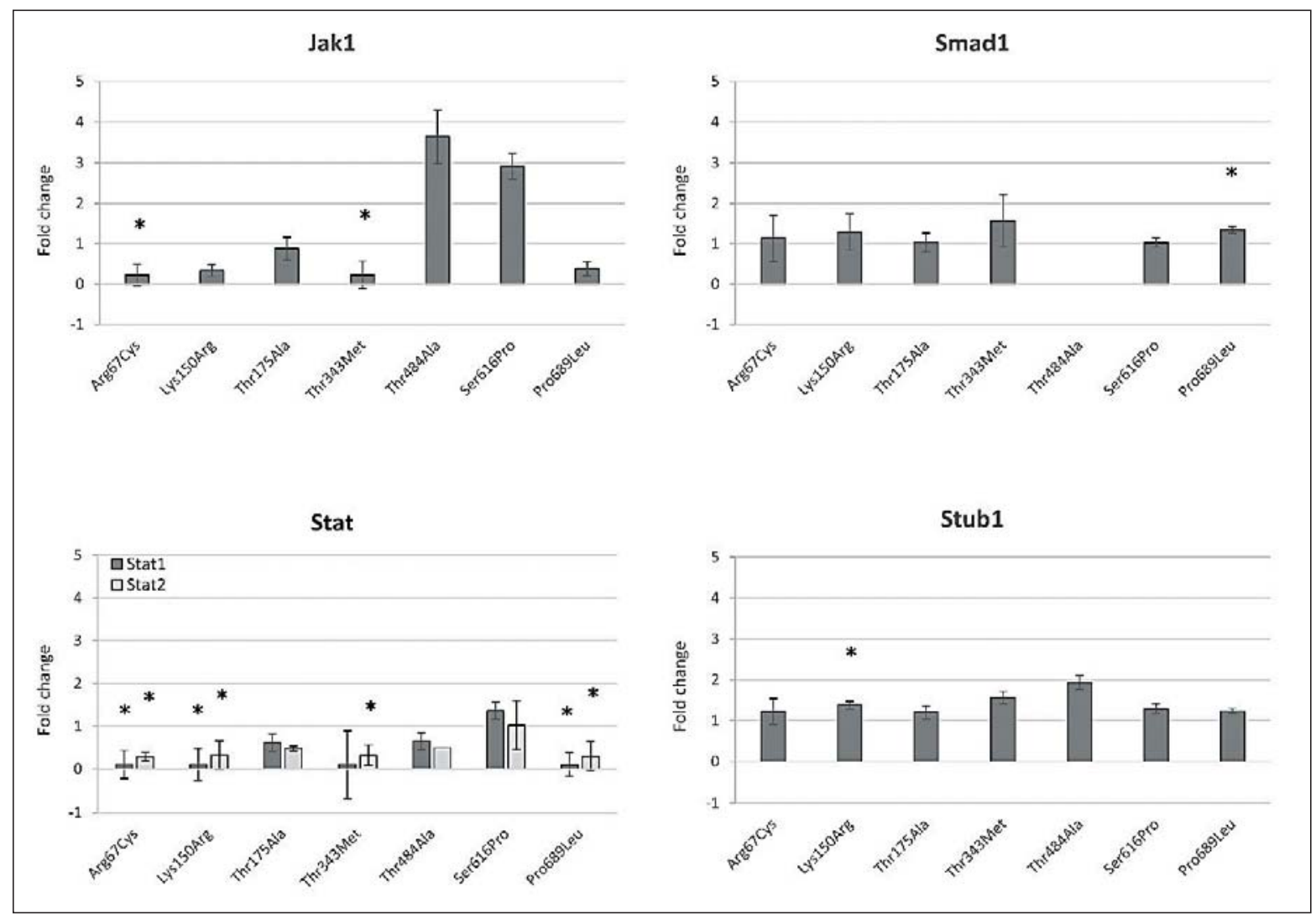

Fig. 1. Genes with expression changes in hypothalamic CLU188 after stimulation with leptin. For the depicted genes, we observed nominal changes in expression (biological triplicate) for at least one of the analyzed $S H 2 B 1$ variants $(p \leq 0.05)$. Fold change from the alpha wild-type splice form is given. ${ }^{*}$ Nominal $p$ value $<0.01$, $* *$ Nominal $\mathrm{p}$ value $<0.001$. Most severe changes in expression were detected for $G b p 2 b$ (67Cys, $\mathrm{p}_{\text {nominal }}=$ 0.0002), Irf9 ( $\alpha 689$ Leu, $\left.\mathrm{p}_{\text {nominal }}=0.000018\right)$, Isg15 (150Arg, $\left.\mathrm{p}_{\text {nominal }}=0.0003\right)$. Gene names: cyclin D1 (Ccnd1); Fatty acid synthase (Fas); guanylate binding protein 2, interferon-inducible (Gbp2b); interleukin 20 (Il20); insulin receptor (Insr); interferon regulatory factor 1 and 9 (Irf1, Irf9); interferon-stimulated gene 15 (Isg15); Janus kinase 1 (Jak1); SMAD family member 1 (Smad1); signal transducer and activator of transcription 1 and 2 (Stat1, Stat2); STIP1 homology and U-Box containing protein 1 (Stub1).

a level that could be analyzed (supplemental fig. 3, available at http://content.karger.com/ ProdukteDB/produkte.asp?doi=486962), 10 showed nominally increased expression ( $\mathrm{p} \leq$ 0.05 ) for at least one of the variants. Expression differences below 0.01 were detected for Cap1 (150Arg, $\left.0.74 \pm 0.08, p_{\text {nominal }}=0.006\right), \operatorname{Mapk1}\left(343 \mathrm{Met}, 1.24 \pm 0.05, p_{\text {nominal }}=0.006\right.$ ), Sorbs1 (689Leu, $0.46 \pm 0.020, p_{\text {nominal }}=0.005$; fig. 2). Here 484Ala did not decrease the expression below the analysis threshold. None of the variants increased the expression of several genes belonging to a specific arm of the signaling pathway downstream of the insulin receptor.

\section{Discussion}

Recent GWAS confirmed association of the chromosomal region 16p11.2 with BMI variation and obesity [4]. SH2B1 most likely contributes to this effect. In a previous mutation screen, we identified seven variants, three of which were non-synonymous [8]. Here, we addi- 
Giuranna et al.: The Effect of SH2B1 Variants on Expression of Leptin- and InsulinInduced Pathways in Murine Hypothalamus

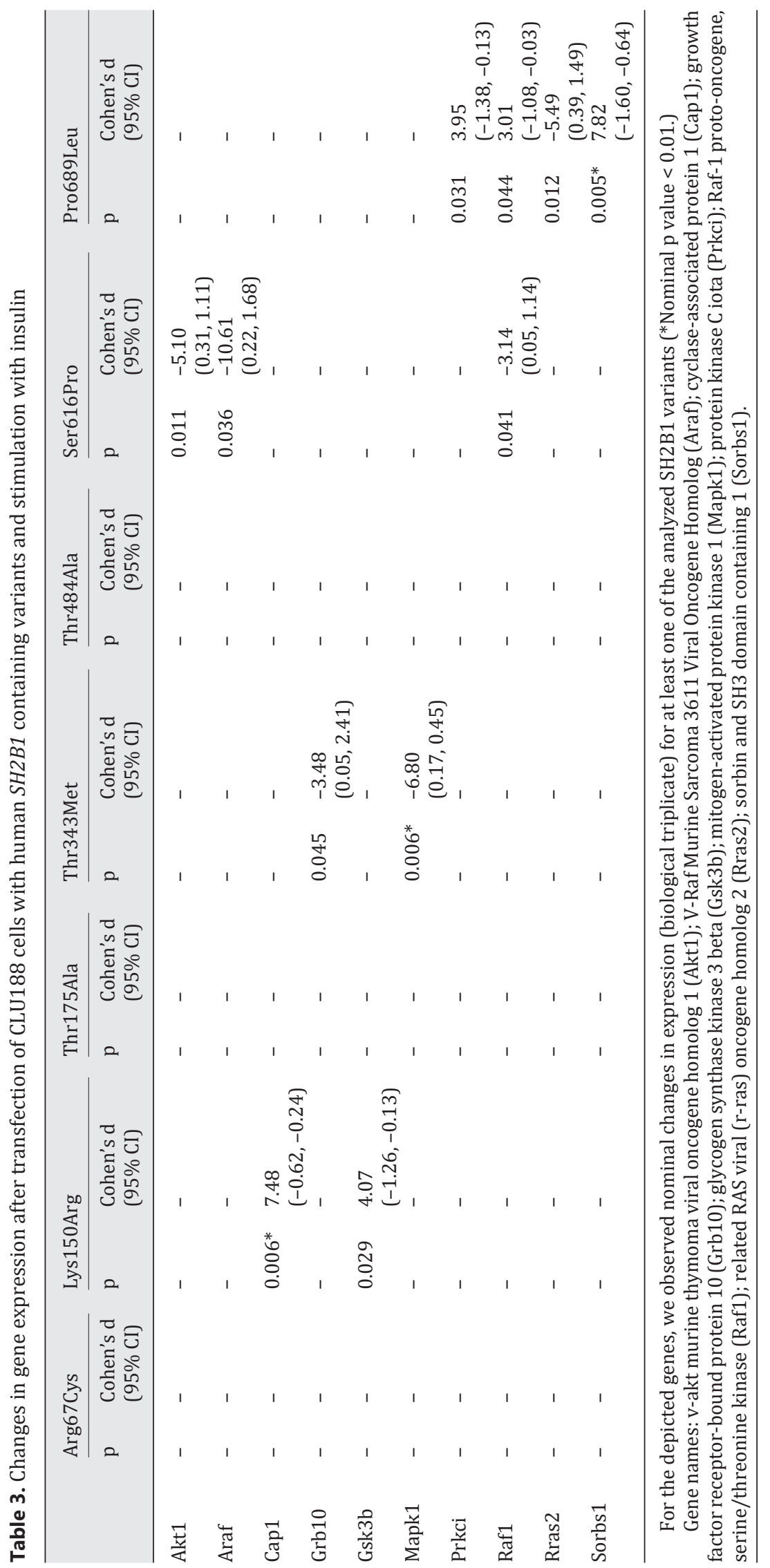


Giuranna et al.: The Effect of SH2B1 Variants on Expression of Leptin- and InsulinInduced Pathways in Murine Hypothalamus

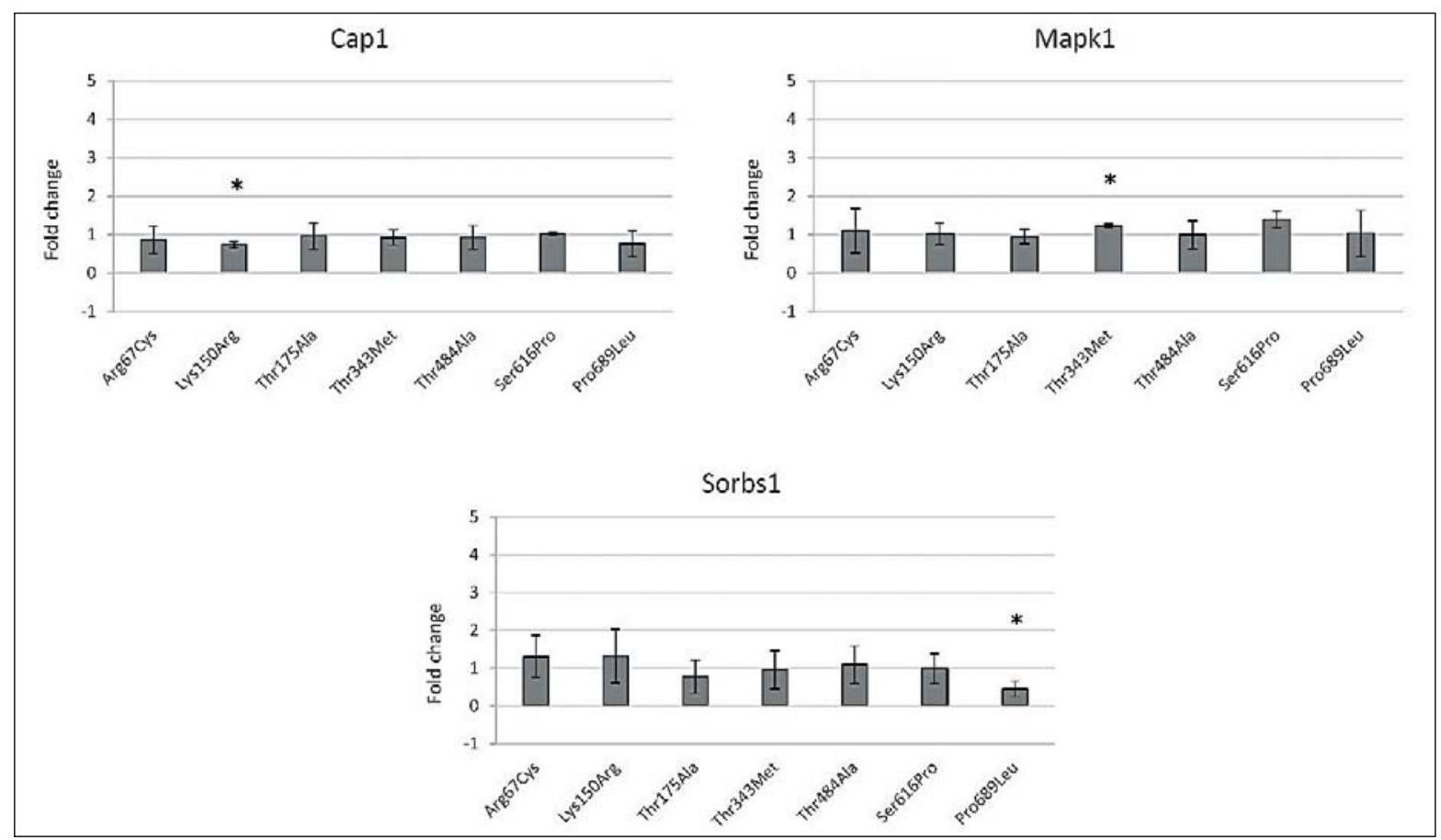

Fig. 2. Genes with expression changes in hypothalamic CLU188 after stimulation with insulin. For the depicted genes, we observed nominal changes in expression (biological triplicate) for at least one of the analyzed SH2B1 variants. Fold change from the alpha wild-type splice form is given. ${ }^{*}$ Nominal p value $<0.01$. Gene names: cyclase-associated protein 1 (Cap1); mitogen-activated protein kinase 1 (Mapk1); sorbin and SH3 domain containing 1 (Sorbs1).

tionally detected a known infrequent variant (Lys150Arg) among 93 lean individuals. We included this variant in our in vitro analysis, as the in silico prediction implied a functional effect of the infrequent allele. The mutated amino acid is located at a key position of the nuclear localization domain of SH2B1. This domain leads to nuclearization of $\beta S H 2 B 1$ which drives the enhancement of NGF-induced neurite outgrowth [26].

In addition, we also analyzed four variants as they potentially entail an altered function based on the following considerations (table 1): i) Functional domain: SH2B1 comprises four main functional domains: nuclear localization domain [25], dimerization domain [20], central pleckstrin homology domain (PH) [32], and the highly conserved amino-terminal SH2 domain [21]. Hence we chose at least one variant for each of these domains. ii) In silico prediction: variants with a prediction (PolyPhen2) of 'possibly damaging' or 'probably damaging' were used. iii) One variant was additionally included; Thr484Ala (rs7498665) because of the previously described obesity association $[1,2,6,8]$.

\section{Expression Analyses}

Variants nominally affected the expression of genes in the leptin and insulin signaling pathways (supplemental fig. 4 and 5, available at http://content.karger.com/ProdukteDB/ produkte.asp?doi=486962). Three genes $(G b p 2 b$, Irf9, and Isg15) were expressed at a higher level by SH2B1 variants (Gbp2b-67Cys, Irf9 - 689Leu, and Isg15 - 150Arg) after stimulation with leptin. STAT1 is activated after leptin stimulation by JAK1 and JAK2 in mice [33]. The transcription factor Stat1 subsequently nuclearizes and binds to the promoter region of Gbp2b [34]. GBP2B contributes to immune system functions against intercellular pathogens 
[35]. Another downstream effector of STAT1 is ISG15, an ubiquitin-like modifier that binds to cytoplasmic and nuclear proteins ISGylating them. ISG15 has not only an anti-viral role, as assumed at the beginning, but also an oncogenic role $[36,37]$. In our study, both direct STAT1 interaction partners showed nominally increased expression for different mutations. The SH2B1 variant 67Cys, located in the dimerization domain, increased the expression of $G b p 2 b$. The C-terminal SH2B1 variant 689Leu increased the expression of Irf9, while 150Arg only affected the expression of Isg15.

IRF9 on the other hand mediates, in response to type I IFN (IFN-I), innate immunity [38]. It forms a complex with STAT1 and STAT2 activating IFN-I-stimulated gene factor 3 (ISGF3) and with it the transcription of IFN-stimulated genes (ISG) [39]. In this process, the interaction of STAT1 and IRF9 is indispensable for binding with a specific DNA sequence called IFN-stimulated response element (ISRE) that is located in the promoter of ISG. Furthermore, STAT2 activates ISRE-containing genes transcription by binding through its topologically associating domain to ISRE [40]. The overexpression of IRF9 in both diet-induced and genetically $(o b / o b)$ obese mice was found to reduce insulin resistance, hepatic steatosis, and inflammation [41]. Although nuclearization of SH2B1 has been shown for the beta, but not the alpha, splice variant of the gene, the differential expression pattern does not have to be a direct outcome of SH2B1 acting as a transcription factor. Whether SH2B1 has to bind specific partners for nuclear shuttling is still unclear [26], although binding of STATs could well be one of them [42].

The panels used for gene expression analysis compared the expression of 84 target genes in the respective pathway with the expression of four housekeeping genes. The average expression of the genes (i.e., the PCR cycle by which the fluorescence signal was above threshold (Ct)) after conversion to delta $\mathrm{Ct}$ (by fitting them to the average $\mathrm{Ct}$ of the four housekeeping genes) occurred between the 24th and 30th cycle. Despite this range which allows detecting diversion to lower expression (up to cycle 35, upper threshold for analysis) or higher expression (down to cycle 20), we only observed expression increases. One explanation would be that additional SH2B1, regardless of introduced variants, would serve as additional signal increaser for both insulin and leptin signaling. Hence, it would increase expression of the target genes without or with very subtle effects of the variants. The only exception was the SNP rs7498665 (484Ala) that decreased expression of 29 of 54 genes. These 29 genes could not be analyzed further as the values were below the analysis threshold. Although a meaningful analysis was not possible, we like to point out that we took care that the RNA amount was exactly the same for all samples (see 'Material and Methods'). Additionally, the biological triplicates all replicated the effect with very little standard deviation (below 5\%, see 'Results'). As the expression of the other genes in the same panel and all housekeeping genes after transfection with SH2B1 Thr484Ala were within the normal ranges, our data suggest that the introduction of 484Ala might lead to aberrantly lower Sh $2 b 1$ expression. However, the method we used precluded a definitive analysis of this assumption.

In contrast to leptin signaling, stimulation of 484Ala-transfected CLU188 cells with insulin did not lead to significant changes in expression of genes related to insulin signaling. Expression of half of the genes of the panel (49 out of 84) was too low for meaningful analyses in the CLU188 cells although expression of housekeeping genes was comparable to the other transfected variants. Nonetheless, expression of the genes Cap1, Mapk1, and Sorbs1 increased by SH2B1 variants (Cap1 - 150Arg, Mapk1 - 343Met and Sorbs1 - 689Leu) after insulin stimulation. CAP1 binds directly to resistin, a hormone that induces insulin resistance and type 2 diabetes in obese mice [43]. In humans, resistin, through insulin/IGF-1R, induces the generation of cytokines and interleukins, which act in a pro-inflammatory manner [44]. SORBS1 which is also called c-Cbl-associated protein (CAP) is involved in the insulin-stimulated transport of glucose into target cells in mice. Insulin mediates the phosphorylation of c-Cbl 
from the c-Cbl-CAP complex, which dissociates from the insulin receptor and binds to other substrates like flotillin in the plasma membrane. This leads to the migration of vesicles containing glucose transporter 4 from cytoplasm to the plasma membrane [45]. A significant association between a polymorphism of the threonine/alanine amino acid substitution at codon 228 (Thr228Ala) of SORBS1 and insulin resistance, obesity, and type 2 diabetes was already detected in a prior case-control study [46]. Furthermore, a recent study found other genetic variants of Sorbs1 significantly associated with blood pressure and hypertension, providing also a possible correlation with insulin resistance [47].

MAPK1, also known as ERK2, is part of the insulin-stimulated MAP kinase pathway. For its activation, recruitment and activation of a number of substrates like RAS or MEK are necessary. This leads in the end to the phosphorylation of ERK1. Once in the nucleus, phosphorylated ERK1 acts on transcription factors inducing proliferation and differentiation [48]. The implication of ERK1 in the regulation of obesity was recently assessed by feeding ERK1 knockout (Erk1-/-) mice a high-fat diet. Erk1-/- mice maintained on this diet were not only more obese but also gained more fat and liver mass than their WT obese counterparts maintained on the same diet. In addition, blood cholesterol, triglyceride, and insulin concentrations were higher in Erk1-/- obese mice compared to wild-type obese animals [49].

Limitations of this study were as follows: i) The knock down of the endogenous SH2B1 only reduced $29 \%$ of the endogenous protein. ii) The sample size was relatively small $(n \leq 5)$. The latter could lead to a lower statistical power and to high false-positive rate [50]. iii) It has to be noted that it cannot be excluded that the SH2B1 variants produce dominant negative effects, since this phenomenon is already known for SH2B1 in mice. For example, some studies described a murine Sh2b1 mutant (Arg555Glu) with an insufficient SH2 domain to function as a negative dominant variant that inhibits IRS1 phosphorylation in cultured cells $[24,51]$ and in transgenic mice [17] causing obesity and insulin resistance. Dominant negative effects in genes have more severe functional impact than other haploinsufficiencies in which only one gene copy remains functional $[52,53]$; it would be of interest to analyze whether the SH2B1 variants here studied have this kind of effect and whether this effect is dose-dependent.

\section{Conclusion}

Our findings suggest that $S H 2 B 1$ variants robustly affect expression of genes in leptin signaling. We detected that SNP rs7498665 (Thr484Ala) decreases expression of genes involved in leptin signaling below the analysis threshold which is to date the first functional impact described for this variant. Taken together, our results suggest that leptin rather than insulin signaling is relevant for the mode of action of $S H 2 B 1$ variants on energy homeostasis.

\section{Grants or Fellowships Supporting the Writing of the Paper}

Deutsche Forschungsgemeinschaft (DFG; HI 865/2-1) and the BMBF (01GS0820). AH and JG were supported by the 'Landesprogramm für Geschlechtergerechte Hochschulen - Programmstrang Förderung von Denominationen in der Genderforschung'.

\section{Acknowledgments}

We are indebted to S. Düerkop and J. Andrä for technical support. 
Giuranna et al.: The Effect of SH2B1 Variants on Expression of Leptin- and Insulin Induced Pathways in Murine Hypothalamus

\section{Disclosure Statement}

The authors declared no conflict of interest.

\section{References}

1 Thorleifsson G, Walters GB, Gudbjartsson DF, Steinthorsdottir V, Sulem P, Helgadottir A, et al. Genome-wide association yields new sequence variants at seven loci that associate with measures of obesity. Nat Genet 2009;41:18-24.

2 Willer CJ, Willer CJ, Speliotes EK, Speliotes EK, Loos RJF, Loos RJF, et al: Six new loci associated with body mass index highlight a neuronal influence on body weight regulation. Nat Genet 2009;41:25-34.

3 Speliotes EK, Willer CJ, Berndt SI, Monda KL, Thorleifsson G, Jackson AU, et al: Association analyses of 249,796 individuals reveal eighteen new loci associated with body mass index. Nat Genet 2011;42:937-948.

4 Locke AE, Kahali B, Berndt SI, Justice AE, Pers TH, Day FR, et al: Genetic studies of body mass index yield new insights for obesity biology. Nature 2015;518:197-206.

5 Renström F, Payne F, Nordström A, Brito EC, Rolandsson O, Hallmans G, et al: Replication and extension of genome-wide association study results for obesity in 4923 adults from northern Sweden. Hum Mol Genet 2009;18:1489-1496.

6 Beckers S, Zegers D, Van Gaal LF, Van Hul W: Replication of the SH2B1 rs7498665 association with obesity in a Belgian study population. Obes Facts 2011;4:473-7.

7 Hester JM, Wing MR, Li J, Palmer ND, Xu J, Hicks PJ, et al: Implication of European-derived adiposity loci in African Americans. Int J Obes (Lond) 2012;36:465-473.

8 Volckmar A-L, Bolze F, Jarick I, Knoll N, Scherag A, Reinehr T, et al: Mutation screen in the GWAS derived obesity gene SH2B1 including functional analyses of detected variants. BMC Med Genomics 2012;5:65.

9 Zheng Z, Hong L, Huang X, Yang P, Li J, Ding Y, et al: Screening for coding variants in FTO and SH2B1 genes in Chinese patients with obesity. PLoS One 2013;8:e67039.

10 Tang L, Ye H, Hong Q, Chen F, Wang Q, Xu L, et al: Meta-analyses between 18 candidate genetic markers and overweight/obesity. Diagn Pathol 2014;9:56.

11 Poveda A, Ibáñez ME, Rebato E: Common variants in BDNF, FAIM2, FTO, MC4R, NEGR1, and SH2B1 show association with obesity-related variables in Spanish Roma population. Am J Hum Biol 2014;26:660-669.

12 Bochukova EG, Huang N, Keogh J, Henning E, Purmann C, Blaszczyk K, et al: Large, rare chromosomal deletions associated with severe early-onset obesity. Nature 2010;463:666-670.

13 Jarick I, Vogel CIG, Scherag S, Schäfer H, Hebebrand J, Hinney A, et al: Novel common copy number variation for early onset extreme obesity on chromosome 11q11 identified by a genome-wide analysis. Hum Mol Genet 2011;20:840-852.

14 Jacquemont S, Reymond A, Zufferey F, Harewood L, Walters RG, Kutalik Z, et al: Mirror extreme BMI phenotypes associated with gene dosage at the chromosome 16p11.2 locus. Nature 2011;478:97-102.

15 Ren D, Li M, Duan C, Rui L: Identification of SH2-B as a key regulator of leptin sensitivity, energy balance, and body weight in mice. Cell Metab 2005;2:95-104.

16 Ren D, Zhou Y, Morris D, Li M, Li Z, Rui L: Neuronal SH2B1 is essential for controlling energy and glucose homeostasis. J Clin Invest 2007; 117:397-406.

17 Morris DL, Cho KW, Rui L: Critical role of the Src homology 2 (SH2) domain of neuronal SH2B1 in the regulation of body weight and glucose homeostasis in mice. Endocrinology 2010;151:3643-3651.

18 Song W, Ren D, Li W, Jiang L, Cho KW, Huang P, et al: SH2B regulation of growth, metabolism, and longevity in both insects and mammals. Cell Metab 2010;11:427-437.

19 Rui L: SH2B1 regulation of energy balance, body weight, and glucose metabolism. World J Diabetes 2014;5: 511-526.

20 Rui L, Carter-Su C: Identification of SH2-bbeta as a potent cytoplasmic activator of the tyrosine kinase Janus kinase 2. Proc Natl Acad Sci U S A 1999;96:7172-7177.

21 Rui L, Herrington J, Carter-Su C: SH2-B, a membrane-associated adapter, is phosphorylated on multiple serines/threonines in response to nerve growth factor by kinases within the MEK/ERK cascade. J Biol Chem 1999;274:26485-26492.

22 Li Z, Zhou Y, Carter-Su C, Myers MG, Rui L: SH2B1 enhances leptin signaling by both janus kinase 2 Tyr 813 phosphorylation-dependent and -independent mechanisms. Mol Endocrinol 2007;21:2270-2281.

23 Nelms K, O’Neill TJ, Li S, Hubbard SR, Gustafson TA, Paul WE: Alternative splicing, gene localization, and binding of SH2-B to the insulin receptor kinase domain. Mamm Genome 1999;10:1160-1167.

24 Duan C, Yang H, White MF, Rui L: Disruption of the SH2-B gene causes age-dependent insulin resistance and glucose intolerance. Mol Cell Biol 2004;24:7435-7443.

25 Doche ME, Bochukova EG, Su H-W, Pearce LR, Keogh JM, Henning E, et al: Human SH2B1 mutations are associated with maladaptive behaviors and obesity. J Clin Invest 2012;122:4732-4736.

26 Pearce LR, Joe R, Doche ME, Su H-W, Keogh JM, Henning E, et al: Functional Characterization of obesity-associated variants involving the $\alpha$ and $\beta$ isoforms of human SH2B1. Endocrinology 2014;155:3219-3226. 
Giuranna et al.: The Effect of SH2B1 Variants on Expression of Leptin- and Insulin-

Induced Pathways in Murine Hypothalamus

27 Hinney A, Hohmann S, Geller F, Vogel C, Hess C, Wermter A-K, et al: Melanocortin-4 receptor gene: case-control study and transmission disequilibrium test confirm that functionally relevant mutations are compatible with a major gene effect for extreme obesity. J Clin Endocrinol Metab 2003;88:4258-4267.

28 Volckmar A-L, Song J-Y, Jarick I, Pütter C, Göbel M, Horn L, et al: Fine mapping of a GWAS-derived obesity candidate region on chromosome 16p11.2. PLoS One 2015;10:e125660.

29 Scherag A, Dina C, Hinney A, Vatin V, Scherag S, Vogel CIG, et al: Two new loci for body-weight regulation identified in a joint analysis of genome-wide association studies for early-onset extreme obesity in French and German study groups. PLoS Genet 2010;6:e1000916.

30 Purcell S, Neale B, Todd-Brown K, Thomas L, Ferreira MAR, Bender D, et al: PLINK: a tool set for whole-genome association and population-based linkage analyses. Am J Hum Genet 2007;81:559-575.

31 Cohen J: Set correlation and contingency tables. Appl Psychol Meas 1988;12:425-434.

32 Wang DS, Shaw G: The association of the C-terminal region of $\beta 1 \Sigma I I$ spectrin to brain membranes is mediated by a $\mathrm{pH}$ domain, does not require membrane proteins, and coincides with a inositol-1,4,5 trisphosphate binding site. Biochem Biophys Res Commun 1995;217:608-615.

33 Bendinelli P, Maroni P, Pecori Giraldi F, Piccoletti R: Leptin activates Stat3, Stat1 and AP-1 in mouse adipose tissue. Mol Cell Endocrinol 2000;168:11-20.

34 Begitt A, Droescher M, Meyer T, Schmid CD, Baker M, Antunes F, et al: STAT1-cooperative DNA binding distinguishes type 1 from type 2 interferon signaling. Nat Immunol 2014;15:168-176.

35 Selleck EM, Fentress SJ, Beatty WL, Degrandi D, Pfeffer K, Virgin HW, et al: Guanylate-binding protein 1 (Gbp1) contributes to cell-autonomous immunity against Toxoplasma gondii. PLoS Pathog 2013;9:e1003320.

36 Sainz B, Martín B, Tatari M, Heeschen C, Guerra S: ISG15 Is a Critical Microenvironmental factor for pancreatic cancer stem cells. Cancer Res 2014;74:7309-7320.

37 Ayub SG, Kaul D: miR-2909 regulates ISGylation system via STAT1 signalling through negative regulation of SOCS3 in prostate cancer. Andrology 2017;5:790-797.

38 Kraus TA, Lau JF, Parisien J-P, Horvath CM: A hybrid IRF9-STAT2 protein recapitulates interferon-stimulated gene expression and antiviral response. J Biol Chem 2003;278:13033-13038.

39 Fu XY, Kessler DS, Veals SA, Levy DE, Darnell JE Jr: ISGF3, the transcriptional activator induced by interferon alpha, consists of multiple interacting polypeptide chains. Proc Natl Acad Sci U S A 1990;87:8555-8559.

40 Stark GR, Darnell JE Jr: The JAK-STAT pathway at twenty. Immunity 2012;36:503-514.

41 Wang X-A, Zhang R, Jiang D, Deng W, Zhang S, Deng S, et al: Interferon regulatory factor 9 protects against hepatic insulin resistance and steatosis in male mice. Hepatology 2013;58:603-616.

42 Su H-W, Lanning NJ, Morris DL, Argetsinger LS, Lumeng CN, Carter-Su C: Phosphorylation of the adaptor protein SH2B1 $\beta$ regulates its ability to enhance growth hormone-dependent macrophage motility. J Cell Sci 2013;126:1733-1743.

43 Li F-P, He J, Li Z-Z, Luo Z-F, Yan L, Li Y: Effects of resistin expression on glucose metabolism and hepatic insulin resistance. Endocrine 2009;35:243-251.

44 Bokarewa M, Nagaev I, Dahlberg L, Smith U, Tarkowski A: Resistin, an adipokine with potent proinflammatory properties. J Immunol 2005;174:5789-5795.

45 Saltiel AR, Baumann CA, Ribon V, Kanzaki M, Thurmond DC, Mora S, et al: CAP defines a second signalling pathway required for insulin-stimulated glucose transport. Nature 2000;407:202-207.

46 Lin WH, Chiu KC, Chang HM, Lee KC, Tai TY, Chuang LM: Molecular scanning of the human sorbin and SH3-domain-containing-1 (SORBS1) gene: positive association of the T228A polymorphism with obesity and type 2 diabetes. Hum Mol Genet 2001;10:1753-1760.

47 Chang T-J, Wang W-C, Hsiung CA, He C-T, Lin M-W, Sheu WH-H, et al. Genetic variation in the human SORBS1 gene is associated with blood pressure regulation and age at onset of hypertension: a SAPPHIRe Cohort Study. Medicine (Baltimore) 2016;95:e2970.

48 Saltiel AR, Kahn CR: Insulin signalling and the regulation of glucose and lipid metabolism. Nature 2001;414: 799-806.

49 Khan AS, Subramaniam S, Dramane G, Khelifi D, Khan NA: ERK1 and ERK2 activation modulates diet-induced obesity in mice. Biochimie 2017;137:78-87.

50 de Winter JCF: Using the Student's t-test with extremely small sample sizes. Pract Assess, Res Eval 2013; 18:12.

51 Morris DL, Cho KW, Zhou Y, Rui L: SH2B1 enhances insulin sensitivity by both stimulating the insulin receptor and inhibiting tyrosine dephosphorylation of insulin receptor substrate proteins. Diabetes 2009;58:20392047.

52 Biebermann H, Krude H, Elsner A, Chubanov V, Gudermann T, Grüters A: Autosomal-dominant mode of inheritance of a melanocortin- 4 receptor mutation in a patient with severe early-onset obesity is due to a dominantnegative effect caused by receptor dimerization. Diabetes 2003;52:2984-2988.

53 Tarnow P, Rediger A, Brumm H, Ambrugger P, Rettenbacher E, Widhalm K, et al: A heterozygous mutation in the third transmembrane domain causes a dominant-negative effect on signalling capability of the MC4R. Obes Facts 2008;1:155-162. 


\section{Erratum}

The article by Giuranna J, Volckmar AL, Heinen A, Peters T, Schmidt B, Spieker A, Straub H, Grallert H, Müller TD, Antel J, Haußmann U, Klafki H, Liangyou R, Hebebrand J, Hinney A: The Effect of SH2B1 Variants on Expression of Leptin- and Insulin-Induced Pathways in Murine Hypothalamus. Obes Facts 2018;11:93-108 was published with some serious errors:

(1) The name of one of the coauthors, Lingyou Rui, was not correctly given: The last name is Rui, and the first name is Liangyou. The correct author names are as follows:

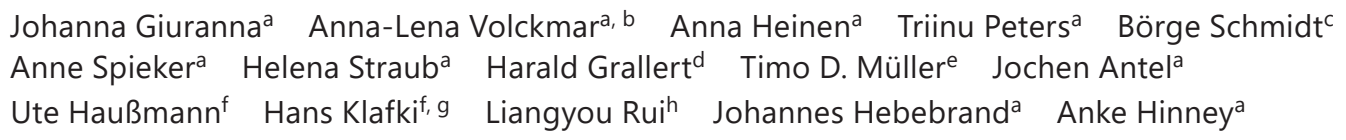

(2) The data included in our manuscript are correct. However, by mistake the point estimation for mean differences was omitted, thus in the Abstract and tables 2 and 3 the text is misleading. The abstract is corrected as follows:

Objective: We aimed to determine the effect of human SH2B1 variants on leptin and insulin signaling, major regulators of energy homeostasis, on the RNA level. Methods: We analyzed the expression of infrequent alleles of seven SH2B1 variants (Arg67Cys, Lys150Arg, Thr175Ala, Thr343Met, Thr484Ala, Ser616Pro and Pro689Leu) in response to insulin or leptin cell stimulation. Two of these were identified in own mutation screens, the others were predicted to be deleterious or to serve as controls. The variants were analyzed in a homologous system of mouse hypothalamic cells. Changes in expression of downstream genes were measured. Student's t-test for independent samples was applied and effect sizes using Cohen's $d$ were calculated. Results: In 34 of 54 analyzed genes involved in leptin (JAK/STAT or AKT) signaling, variants nominally changed expression. The expression of three genes was considerably increased ( $p$ values $\leq$ 0.001: Gbp2b (67Cys; $d=25.11$ ), Irf9 (689Leu; $d=44.65$ ) and Isg15 (150Arg; $d=20.35)$ ). Of 32 analyzed genes in the insulin signaling pathway, the expression of 10 genes nominally changed $(p \leq 0.05)$, three resulted in $p$ values $\leq 0.01$ (Cap1 (150Arg; $d=7.48)$, Mapk 1 (343Met; $d=-6.80$ ) and Sorbs1 (689Leu; $d=7.82)$ ). Conclusion: The increased expression of genes in leptin (JAK/STAT or AKT) signaling implies that the main mode of action for human SH2B1 mutations might affect leptin signaling rather than insulin signaling.

(3) Corrected versions of tables 2 and 3 are also given. 


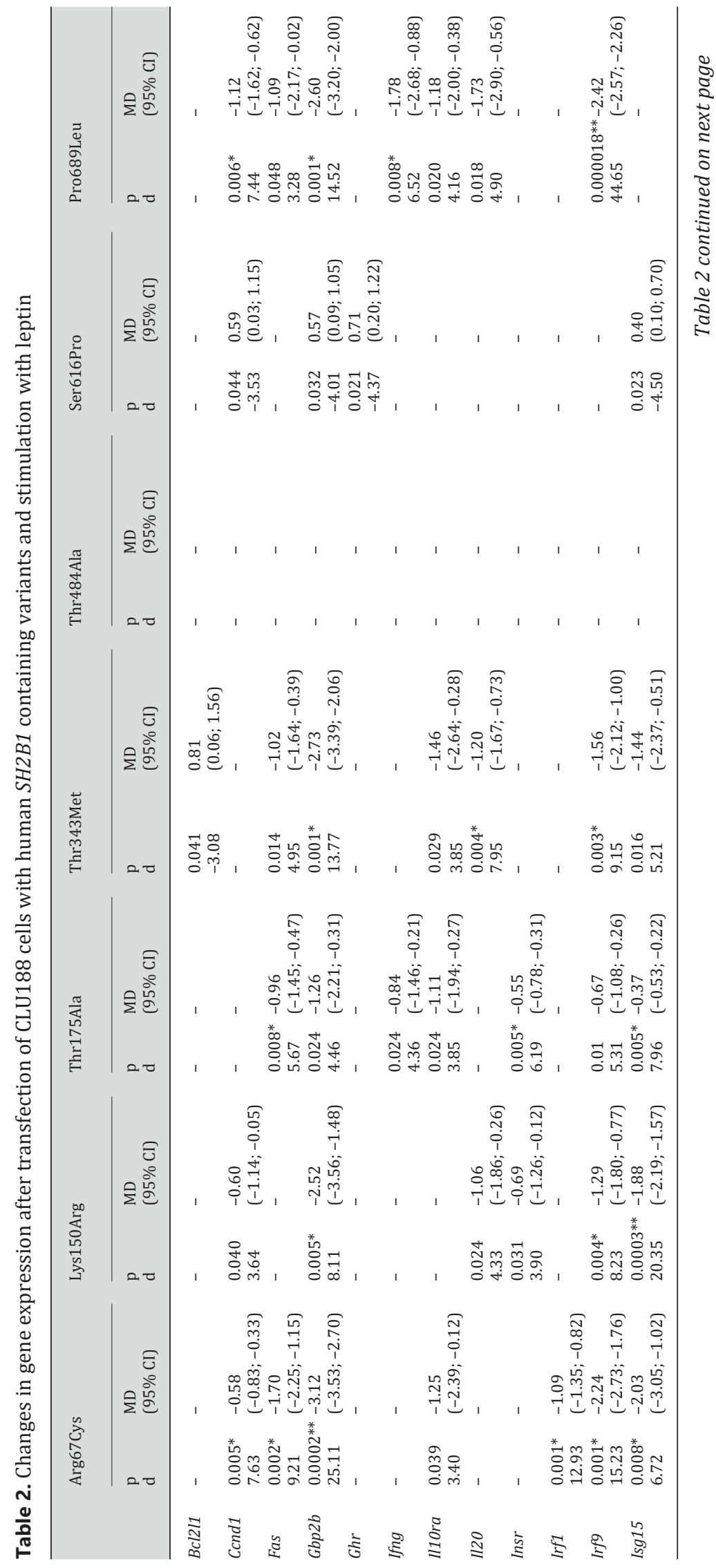




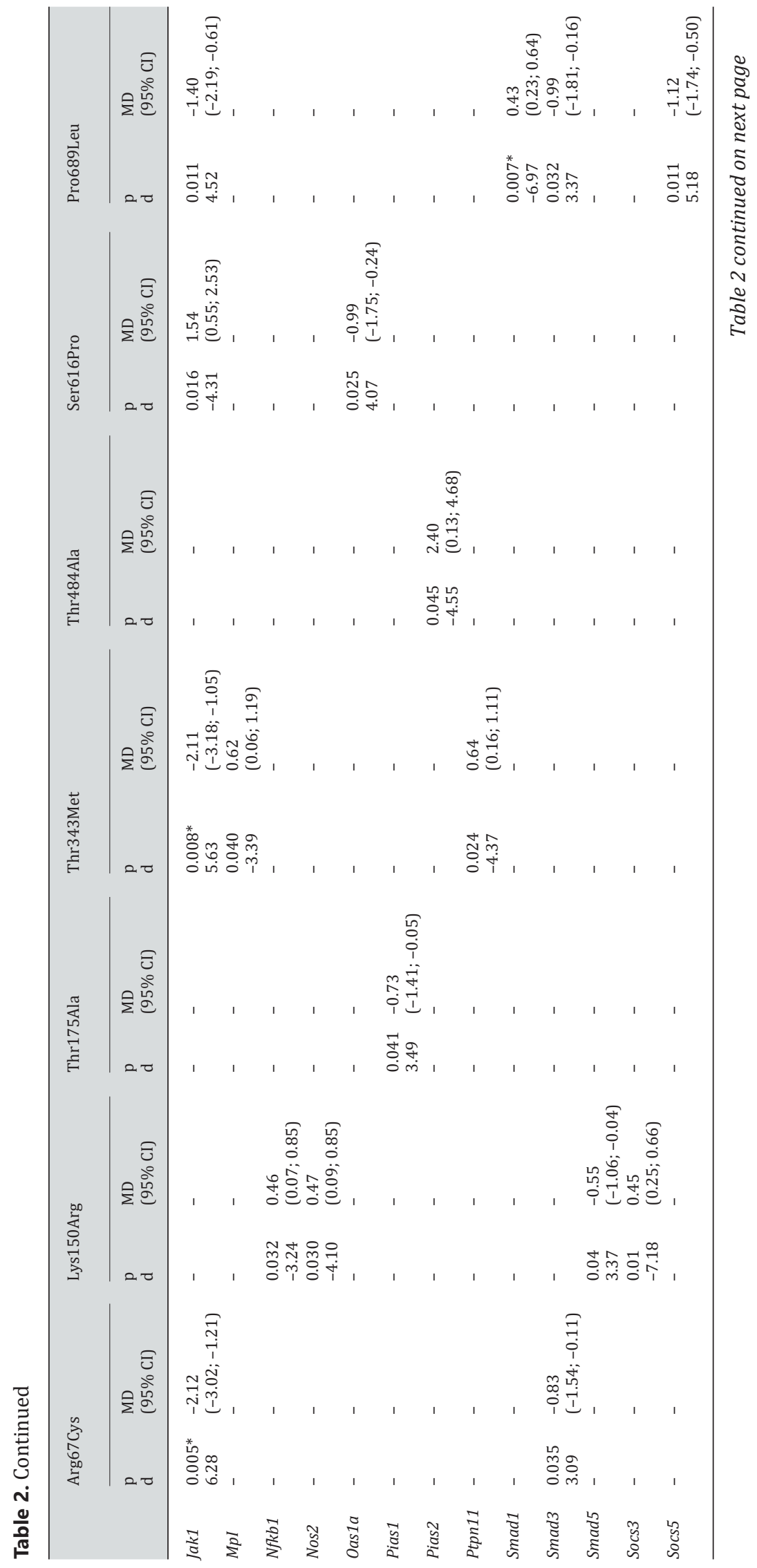



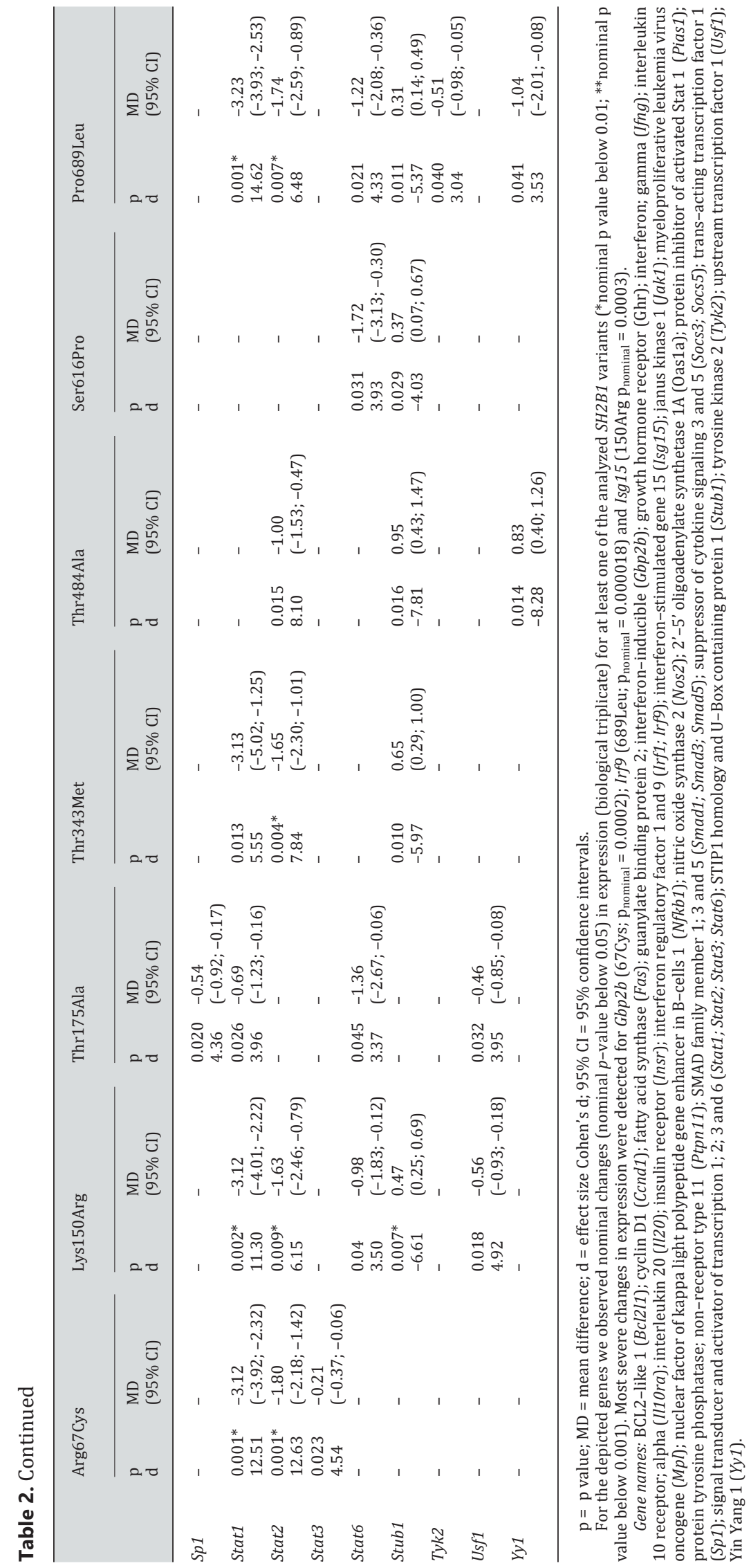


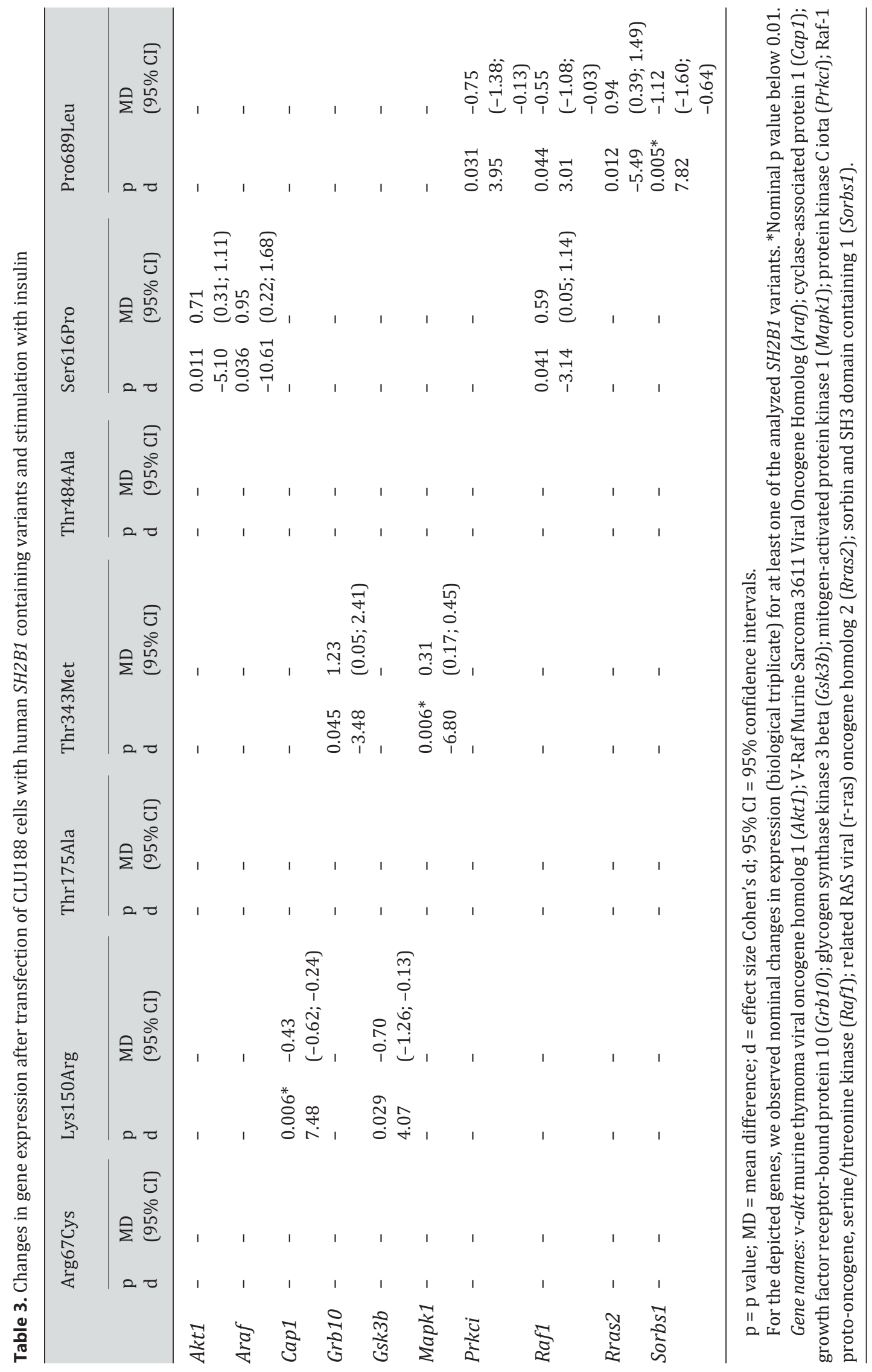

